\title{
EXPERIMENTAL MANNERS OF A INTERFERENCE REDUCTION OF CHOSEN MEASURING SIGNALS OF A GENERATING SET IN CONDITIONS OF A MARINE POWER PLANTS
}

\author{
Jan MONIETA, Marcin NOWICKI \\ Maritime University of Szczecin, Faculty of Marine Engineering, j.monieta@am.szczecin.pl
}

Abstract

The article presents problems occurring during the signals processing of the parameters of working processes of internal combustion engines in tests, while powering the measuring apparatus from the electric network of the marine power plant laboratory. Various experimental methods of separation were used to identify and then eliminate interference. On the basis of analyses carried out in the domain of time and frequency of the in-cylinders pressure signals of internal combustion engines and their wavelet decomposition, attempts were made to determine and eliminate the sources of interference. It has been shown that interference was penetrating the measuring equipment through the supply network. The developed methods of reducing interference in the laboratory conditions can be applied on the marine vessels. On the basis of the conducted tests, it can be concluded that the reduction of interference of pressure measurement signals in the engine cylinder is most effective when the computer is powered only from the battery while the measuring circuit is powered directly from the power network.

Keywords: marine power plants, generating sets, in-cylinder pressure courses, interference

\section{EKSPERYMENTALNE SPOSOBY REDUKCJI ZAKŁÓCEŃ WYBRANYCH SYGNAŁÓW POMIAROWYCH ZESPOŁU PRĄDOTWÓRCZEGO W WARUNKACH LABORATORIUM SIŁOWNI OKRĘTOWYCH}

Streszczenie

W artykule przedstawiono problemy występujące w czasie przetwarzania sygnałów parametrów procesów roboczych $\mathrm{w}$ badaniach silników spalinowych, przy zasilaniu aparatury pomiarowej $\mathrm{z}$ sieci elektrycznej laboratorium siłowni okrętowej. Dla identyfikacji i następnie eliminacji zakłóceń zastosowano różne eksperymentalne metody ich separacji. Na podstawie wykonanych analiz $\mathrm{w}$ dziedzinie czasu i częstotliwości sygnałów ciśnienia w cylindrach silników spalinowych oraz ich dekompozycji falkowych próbowano ustalić źródła zakłóceń oraz je eliminować. Wykazano, że zakłócenia przedostają się do aparatury pomiarowej przez sieć zasilającą. Wypracowane sposoby redukcji zakłóceń w warunkach laboratoryjnych mogą być zastosowane na statkach morskich. Na podstawie przeprowadzonych badań można stwierdzić, że redukcja zakłóceń sygnałów pomiarowych ciśnienia w cylindrze silnika jest najskuteczniejsza, gdy komputer zasilany jest tylko $\mathrm{z}$ baterii, a tor pomiarowy bezpośrednio z sieci elektroenergetycznej.

Słowa kluczowe: siłownie okrętowe, zespoły prądotwórcze, przebiegu ciśnienia cylindrowego, zakłócenia

\section{INTRODUCTION}

A sea-going ship is an object with a high concentration of machinery and equipment, which are the source of electrical interference. In power installations there are network disturbances caused by uneven engines speeds and in particular by rapid and sometimes significant engine load changes. The basic components of the ship's electrical power system are [3]: power sources, main and auxiliary switchboard, cable network and various electricity consumers.

Undesirable signals called interference and noises always appear in electronic circuits $[1,3]$. An undesirable signal is any signal occurring in the measuring system, other than the useful one [3]. Interference is one of the undesirable signals that cause malfunction of an object or measurement system. Most often, undesirable signals cannot be completely eliminated, but their level can be lowered. Due to the source of the disturbance can be divided into [3, 14, 15]: mechanical, environmental, electrical (internal noise, time fluctuations, signals from energy elements, galvanic, electrolytic, triboelectric, navigation signals, switching and control signals lighting etc.). Interference causes malfunction of an object or system and may cause gradual and sudden damage. The disturbances also adversely affect the diagnostics of supervised objects $[7,9,14,15]$.

Disturbance of the measurement signals is caused by the flow of the working medium in the piston internal combustion engine: delay of pressure wave in a channel, a local and line losses 
of pressure in the channels, pressure pulsations of medium in the channel, etc. Interferences can also be generated in measurement system components such as sensors, analog-to-digital converters, computers, etc. Also environmental conditions are affecting the interference level [7].

Measurements of parameters of working processes such as temperature, pressure, flow velocity, vibration, etc., are performed by electronic sensors, and readings of measured parameters are presented on indicators or on the computers of the ship. Often happens so that the measuring circuit from the sensor to the meter is very long, complicated and extends to the different spaces of the marine propulsion plant [6]. This results in the exposure of electronic devices (pressure sensors, amplifiers, analog-digital cards, etc.) to mechanical vibration, variable ambient conditions, and electromagnetic fields, which cause disturbance in measurement and control equipment [7, 12, 15].

It is advisable to reduce the interference of measurement signals in order to increase the accuracy of the measured values in the monitored systems, which will contribute to credible diagnostics and controlling of operation process and will allow a quick response in the event of deviations from the expected operation.

\section{TYPES AND SOURCES OF INTERFERENCE}

The most frequently occurring interference are the periodical interference and measurement phases switching interference [3]. Disruptions can overlap each other to the processed signal, leading to erroneous measurement results. The nature and intensity of interference depend on many factors. Disturbances in power systems are varied. The manner of the division of disruptions depends from adopting the defined criterion. Distinguishing the character of physical phenomena, which are the primary cause of interference, can be divided interferences $[3,4]$ :

- mechanical (e.g. vibrations, shocks, impacts);

- biological, associated with the flora and fauna and related to living and non-living environment and with environmental conditions (e.g. changes of temperature, humidity and pressure, presence of mushrooms, mould and dusts);

- electric (internal noise of elements and electronic systems, time drifts, triboelectric effects, signals of radio transmitters, signals from switching and ignition elements, signals from power lines, signals coming from electrical devices)

Due to the mathematical description, electrical interferences, as well as useful signals, are divided into determined and undetermined interference. The determined ones are described by means of mathematical relationships are described by means of mathematical relationships. The second one, called accidental or random, are difficult to describe with exact mathematical relationships, since the result of each signal observation is unique. Practically these signals are described by the values of statistical nature [14]. Theoretical models of the sources of interference are usually approximate.

The literature shows that one of the disturbed signals are the pressure courses in the cylinders of the piston internal combustion engines $[5,9,12]$. From the inside of the cylinder, the pressure rises violently after the combustion process begins, forming a standing resonant wave after reaching the pressure sensor, which significantly affects the quality and accuracy of the recorded pressure by introducing undesirable interference $[2,5]$.

F. Payri and other [10] presented a concept of the distribution of the pressure signal in order to conduct an analysis of the noise of the course of the combustion process. The authors have been shown the results obtained from the proposed decomposition technique exhibit a fair qualitative correlation between in-cylinder pressure and combustion noise issues.

\section{ELEMENTS AND SUB-ASSEMBLIES SUPPRESSING INTERFERENCE SIGNALS}

There are possibilities of passive and active controlling of the level of interference in the ship's network and measuring circuits. Controlling the level of interference and noise is the use of structural and technological solutions that eliminate or significantly reduce interferences $[3,14,15]$. The most commonly used techniques in this field include: shielding, smoothing chokes, multi-pulse propulsion systems, phase shift transformers also passive and active filters $[3,5,11,12,15]$.

Suppression is the reduction in amplitude, measured in $\mathrm{dB}$, to which the signal is exposed after passing through the digital filter. The antiinterference suppressing element is the ratio, at a given frequency, the signal amplitude at an output to the amplitude of the input element [7]. An additional improvement in the metrological properties of analogue-to-digital converters can be obtained by fully automatic signal synchronization with the input signal or interference signal. The interference caused by overvoltage during instrument switching can be reduced by triple integration.

In order to reduce the level of undesirable signals and reduce their ability to cause the interference in the functioning of electronic devices, capacitors, chokes, elements with nonlinear current-voltage characteristics and filters with preset frequency characteristics response and digital filters are commonly used [3, 5, 11, 12]. Such elements and sub-assemblies are being used in the case for appearing of impulse disruptions about great intensity for the protection of circumferences and electronic systems (particularly semiconductor) before damage. 
Depending on the conditions of operation of the device (interferences level, strips of suppressed frequencies, type of interferences) different kind of capacitors are used [6]. Anti-interference capacitors are designed mainly to suppress undesirable signals occurring primarily in direct current (DC) and alternating current $(\mathrm{AC})$ power circuits [3].

A special types of chokes are ferrite elements of a suitable shape, so-called ferrite beads, located around the wires. Used primarily in wideband systems (for example, placed in the perimeter of the base of the transistor, on power cables of amplifiers and generators of high frequencies or on comparatively long wires). The chokes counteract interferences transferred by conduction and exciting of parasitic vibrations caused by couplings and resonances.

Chokes are inductive coils whose impedance is of high value and the DC resistance is negligible. They are used in electronic devices to suppress undesired components of signal at frequencies outside the bandwidth occupied by useful signal. Chokes characteristics such as dependence of goodness and impedance (insertion loss) on frequency, changes of inductance and acceptable current from ambient temperature are helpful information the correct selection of chokes in a given application.

Chokes are in the form of air coils or magnetic coils (magnetic or ferromagnetic cores) - open or closed. Air chokes or open magnetic cores are the source of interference due to the presence of dispersed magnetic fields. Limitation of the spread of the magnetic field is achieved by using magnetic material screens.

However, there is no suppression of the fixed and low frequency components. Below the a dozen or so megahertz, the inductive component of the impedance dominates, which is associated with the occurrence of the reflection of the interfering signal.

Transformers are commonly used to separate electrical circuits. Transformers are used to separate electrical circuits, especially power supply circuits [3]. This solution allows eliminating the flow of disturbance currents in the ground loop. In this case, a good way of coupling the circuits is by magnetic field only. Reduction of the effect of $\mathrm{C} 12$ parasitic capacitance between the primary and secondary windings of the transformer, which causes harmful electrical coupling and interference to the secondary circuit, is achieved by using electrostatic screens or grounded conductive wires between the two windings.

Such shielding does not affect magnetic coupling, but eliminates capacitive coupling when the screen is grounded. The screen should be attached to the ground plane in the secondary circuit point [3].

The transformer in this configuration is called a neutralizing or symmetrizing. Interference currents caused by the voltage difference, flowing in both cables in the same direction and for them the windings represent a high impedance. Such a solution provides an interruption for the coupling loop between the circuits compared to the situation to what would have been the case had these circuits been directly connected [3].

\section{THE USE OF ELECTRONIC FILTERS}

The authors of the work $[5,13]$ presented the use of electronic filters in the pressure measurement in a combustion chamber of the internal combustion engine. In these publications the applying of filters was the main manner of the reduction in interferences of the measuring of pressure signal in the combustion chamber. The Chebyshev filter ripples showed produced the best results in matching the raw signal near the combustion startup and minimizing oscillations after the start of combustion [13]. The filter is characterized by partial loss of signal on the way it is located [5]. This is the so-called insertion loss of the filter, which is the signal level remaining after the filter is switched on, referenced to the level observed in the same point without filter. The research object was the Sulzer marine engine, where one of the basic engine subsystems is built into the pressure stub pipe for continuous monitoring of the working process in the cylinder.

The expectation is the rejection of these pressure pulsations and characterisation of the noises, which can lead to an erroneous determination of the various parameters and characteristics of the combustion process [14]. These activities focus on filtering out disrupted data of pressure line, so as to eliminate the need for any subsequent analysing of combustion process and the noise analysis. The filtering algorithm is defined as a combination of a five point filter of the moving average and a low- and high-pass Butterworth filter.

The filter was tested for resistance to various engine operating conditions such as engine load, rotational speed, increases, etc. The filter cut off frequency is determined on the basis of the degree, according with the algorithm using the dependent on the spectral density of the power, pressure signal. The noise component has been separated from the pressure course by the noise spectrum distribution technique and an access of the passage through resonance frequencies is assigned.

\section{RESEARCH PROBLEM}

Interference with mechanical signals measured by electrical methods occurs both in the actual power plant of the ship and in the marine power plants laboratory where the same machines are located. The measuring circuit was powered by the ship's power socket with the voltage AC $230 \mathrm{~V}$ or power network of Marine Power Plants Laboratory in Maritime University of Szczecin. The tests in 
ship conditions can be performed periodically when in national ports, because the ships typically reside on the seas and oceans. In conditions of the laboratory of marine power plant it is possible to carry out research in the constant way and to transfer their results on the marine vessels.

The conditions in the actual marine power plant from the conditions in the laboratory $[8,9]$ :

- significant level of vibration and noise caused by the operation of other objects of the marine propulsion plant,

- changes in the voltage and frequency of the ship's network affecting the measuring instruments,

- change torque of internal combustion engines as the result of continuous changes of the value of the demanded power,

- changes of the value of the reference parameters.

The review section of the article presents the hitherto achievements of interference reduction described in the literature. It contains the description of methods and elements and subassemblies applied for the interferences reduction. The aim of the experimental parts is test methods for interferences reduction and estimating their effectiveness and usefulness's are for the application.

The realisation of the work was the experimental testing of various methods of interference reducing of the measurement signals of working processes of reciprocating self-ignition engines and modernization of the measuring circuit on the basis of test results. The researches covered of in-cylinder pressure course in cylinders of medium-speed engine of generator set depending on the time or the crankshaft position.

The choice of the course of pressure in the cylinder as the signal, on the example of which the tests were carried out, was determined by a significant application of this process in the diagnostics of piston combustion engines. A good knowledge of the phenomena of this process, the sources and the form of interference, and the analysis of such signals allows a credible assessment of the results obtained [12].

After analysing up-to-date activities in this respect, it was investigated whether the reduction of measuring signal interference is possible and how effective.

\section{TEST METHODS}

The measurement circuit consisted of strain pressure sensor, amplifier, power supply, 16 analog inputs via BNC connector's terminal connection and a laptop with Daq/216B analog-to-digital card [7, 8]. The Daq/216B built-in 16-bit analog inputs permit it to measure 16 channels in a single-ended. Sixteen-channel signal acquisition system and DaqView signal analysis program with a sampling frequency of $100 \mathrm{kHz}$ were used.
DaqView allows you to verify signal concentration, acquire and save data to disk, and graphically view real-time data. DaqView is a 32 bit Windows-based data acquisition program that can be used to operate a variety of related data acquisition products. DaqView allows you to: set up system parameters, select channels, gains, transducer types, etc. To acquire data it is possible to save to disk and transmit to spreadsheets and databases. This software allows you to make settings, visualize the results of the measurements and save them in real time.

When analog is selected the user has the choice of adding a scope which exhibits one of the following functions: raw time, filter, averaged time, windowed time, decimated time, frequency transform, rms time, spectrum analysis. To display meaningful data, the spectrum analysis mode requires a minimum of three complete waveform cycles.

The circuit was powered from the marine power network from the $230 \mathrm{~V}$ AC outlets or the network of Marine Power Plant Laboratory of Maritime University in Szczecin. Any signal transmission was made using shielded cables. The research was conducted with the help of the pressure gauge sensor PT-5101 type $\mathrm{H}$ series about measuring range 0-16 $\mathrm{MPa}$, cooperating with the measuring amplifier AT-5230 type. The in-cylinder pressure signals of the internal combustion engine were analysed in the frequency range $0-0.1 \mathrm{kHz} ; 0-2.5$ $\mathrm{kHz}$ and $0-10 \mathrm{kHz}$.

In the studies not interference suppression to the place of occurrence, but uses the device and connection systems with increased resistance to interference with the following solutions:

- powered of measurement circuit from $230 \mathrm{~V}$ network and computer from the power supply;

- powered of measurement circuit from $230 \mathrm{~V}$ network and the computer not from the AC power supply, but the battery;

- powered of measurement circuit from $230 \mathrm{~V}$ network indirectly by a separation transformer 230/230 V and computer from power supply,

- power measurement circuit with the network $230 \mathrm{~V}$ indirectly by separation transformer 230/230 V and powered the computer from battery;

- powered measurement circuit using a feeder UPS.

Often there is the need for appropriate smoothing of interference pressure signal course, which can be made using the wavelet decomposition or other methods. The saw shapely disturbances observed after the moment of ignition are caused by a short gas duct between the combustion chamber and the sensor whose presence has been forced by technological considerations.

Spectrum interferences are occurs at taking and sampling of the signal, and especially at the transform of the signal from the time-domain into 
the frequency domain. In order to avoid sampling error, the low-pass filtering of signal must be performed. To avoid of the aliasing phenomenon, it is recommended to perform low pass filtering for $f_{g}$ $<f_{N y q}[14]$. This can be achieved by using tunable analog filters. Low-pass filtering eliminates the information transferred by high-frequency signal components, therefore one should establish the border frequency $\left(f_{g}\right)$ of the filtration in preliminary examinations.

\section{TECHNICAL DATA OF THE INVESTIGATED OBJECT AND MEASUREMENT EQUIPMENT}

Examinations concerned the generating set with the Zgoda Sulzer 5BAH22 engine type and a threephase generator. Technical data of the self-ignition engine:

- nominal power $220 \mathrm{~kW}$,

- rotational speed (constant) $500 \mathrm{rpm}$,

- way of working 4-stroke turbocharged,

- cylinder diameter $220 \mathrm{~mm}$,

- piston stroke $320 \mathrm{~mm}$.

Technical data of the generator:

- apparent power $250 \mathrm{kVA}$,

- generator voltage $400 \mathrm{~V}$,

$-\cos (\varphi)=0.8$.

The power pack of the computer was of type

Computer Corporation Compaq, AC with the PPP012L power supply about input parameters:

- voltage: $100 \div 240 \mathrm{~V}$ (alternating current),

- current intensity of $1.5 \mathrm{~A}$,

- frequency 50-60 Hz.

Output parameters:

- voltage 18,5 V (direct current),

- current intensity $4.9 \mathrm{~A}$,

- power $90 \mathrm{~W}$.

Strain gauge pressure sensor works by measuring the elastic deformation of the measuring element under the influence of the applied pressure. The measuring element is a membrane, which is an integral part of the sensor body, with strain gauge foil glued in the bridging system. The acting pressure causes deforming the membrane or sleeve and resistance change in the strain gauge system. Pressure sensor PT-5101 collaborated with measuring amplifier AT-5102 type with the cassette panel about $0 \div 10 \mathrm{~V}$ or $4 \div 20 \mathrm{~mA}$ output signal.

The system has the jumping or fluid change of amplifier gain, adjust the zero of the amplifier and the excitation voltage of the strain gauge bridge. The layout is characterized by independent zero and gain control, good linearity and small temperature driftings of parameters.

For the interferences reduction the TS $1000 \mathrm{VA}$ $230 \mathrm{~V} / 230 \mathrm{~V}$ separation transformer was purchased in the casing (Fig. 1) with the following parameters:

- power of $1000 \mathrm{VA}$,

- supply voltage $230 \mathrm{~V}$,
- output voltage $230 \mathrm{~V}$,

- electric strength of insulating material PRI/SEC $4 \mathrm{kV}$.

Power supply ups were used with the following data:

- apparent output power $650 \mathrm{VA}(400 \mathrm{~W})$,

- range of voltage tolerated $220 \div 240 \mathrm{~V}$,

- input voltage frequency $50 / 60 \mathrm{~Hz}$.

The electric motor of the air compressor had the following rating data:

- power $21 \mathrm{~kW}$,

- rotational speed $975 \mathrm{rpm}$.

Fig. 1 shows the view of the power supply from the $230 \mathrm{~V}$ mains via the separation transformer and the anti-interference filter.

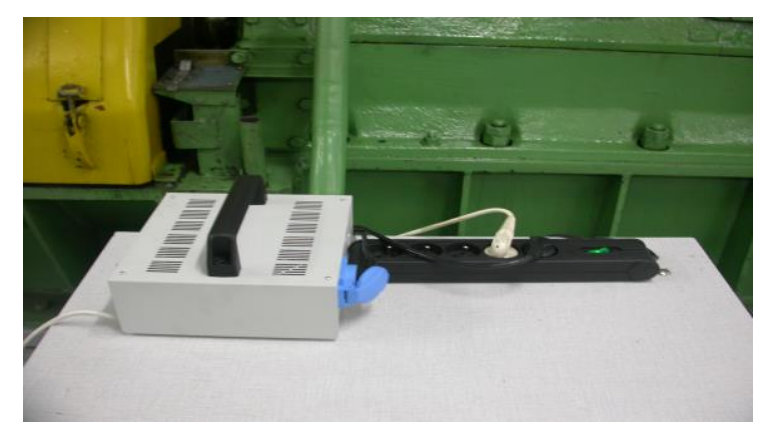

Fig. 1. The power supply of the measuring circuit using separation transformer and anti-interference filter

\section{TEST RESULTS}

\subsection{Dependencies describing noised signals}

The signal processed by the sensor at the place of $r$ can be written according to the equation:

$$
S(r, \tau, \theta)=\sum I_{i}\left(\tau, \theta, r_{i}\right)^{*} S_{i}\left(\tau, \theta, r_{i}\right)+S_{n}(\tau, \theta, r)+z(r, \tau, \theta)
$$

where: $I_{i}\left(\tau, \theta, r_{i}\right)$ - set of impulse characteristics, $S_{n}(\tau, \theta, r)$ - nominal signal of functioning of the object, $\mathrm{z}(r, \tau, \theta)$ - interferences generated in the functioning object, $i$ - finite a string of indices, $\tau-$ dynamic time, $\theta$ - time of object existence.

The course of in-cylinder pressure noisy signal of the combustion engine $P_{s}$, unfiltered consists of the compression, combustion and noise process depending on the time or angle of rotation of the crankshaft can be decomposed into components:

$$
P_{s}=K(\theta)+C(\theta)+Z(\theta)
$$

where: $K$ - compression process, $C$ - combustion process, $\mathrm{Z}$ - noise.

The in-pressure courses have most often been received of internal combustion engines about slight interferences [8], but there were happened the signals significantly disturbed [9]. These were disturbances that persisted in established states. Impulse waveforms appearing in power supply networks cause $90 \%$ of interferences of computer devices [3]. 
Voltage interferences can be assessed by means of the voltage distortion indicator:

$$
K_{u}=\frac{\sqrt{\sum_{n=2}^{\infty} \tilde{U}_{i}}}{\tilde{U}_{c}} 100 \%
$$

where: $\tilde{U}_{i}$ - root-mean-square value of the $i$ voltage component, $\tilde{U}_{c}$ - root-mean-square value all over of the voltage course in time domain.

Interference can be determined, which can be described by mathematical relations, or randomly described by means of statistical quantities, like as amplitude estimates [3, 15]: root-mean-square value, mean value, power spectral density, probability density. There is the need to eliminate signal disturbances that may be useful in the diagnostics of marine power plants, ie. smoothing out the course or identifying disturbances themselves [12]. Averaging over time replaces the fluctuation size by the constant values equivalent to:

$$
\bar{P}_{s}=\lim _{T \rightarrow \infty} \frac{1}{T} \int P_{s}(\tau) d \tau
$$

where: $\tau$ - time, $T$ - period.

The matrix takes into account the random errors $e_{i}$ (measuring, the methodologies, disruptions coming from the environment, factors not taken into account in the matrix:

$$
E=\left[e_{1}, e_{2}, \ldots, e_{n}\right]^{T}
$$

From the descriptions of critical damage to the piston internal combustion engines it follows that they are often preceded by interferences of some diagnostic parameters measured a selected point of space of the examined object. Such disruptions are being signaled through:

- significant dispersion of results of measurements;

- of the change of the average value of the parameter (arithmetic means, geometrical means, modal means and coefficients of variation).

The cause of the variation in results may be mechanical wear or damages to the object components.

Disturbed signals can be subjected to a multidimensional de-noising procedure. This is a generalization of one-dimensional noise reduction procedure. The disturbed signal the $S_{z}$ in accordance with work Aminghafari [1] and others can be written assuming $n$-dimensional model of the signal:

$$
S_{z}(\tau)=S(\tau)+\varepsilon(\tau), \tau=1, \ldots, n
$$

where $\varepsilon(\tau)$ - Gaussian noise with the unknown covariance matrix.

\subsection{Signals analysis in the time and frequency domain}

Before the commissioning of the generator set, an air compressor driven with electric motor was enclosed was started and in the measuring circuit of cylinder pressure appeared interference as shown in Fig. 2. The startup of the marine piston engine is carried out using compressed air.

The spectrum is shown in the frequency $0 \div 100$ $\mathrm{Hz}$ because only in this compartment were interesting components. The figure shows that a significant component of this interference has the frequency of $4 \mathrm{~Hz}$, which corresponds to $1 / 4$ of the rotary speed of the air compressor.

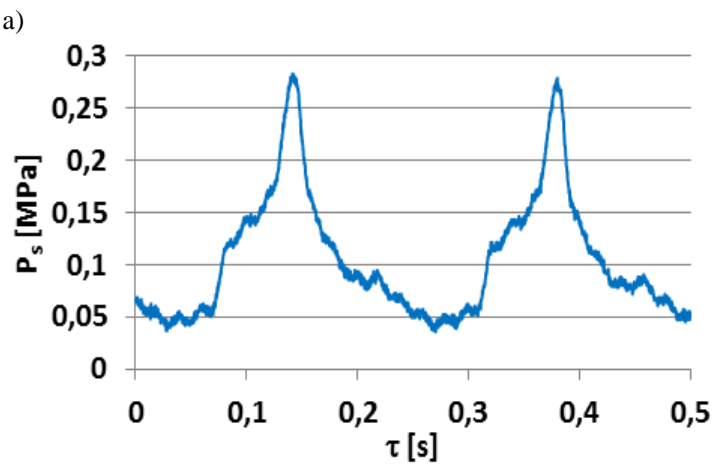

b)

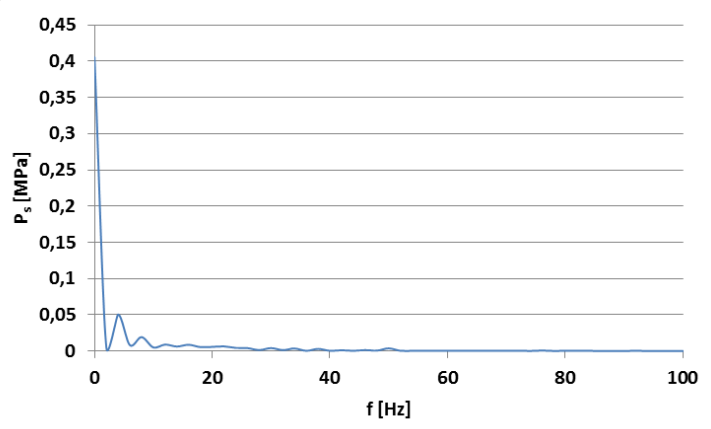

Fig. 2. Fig. 2. Time-domain a) and spectrum b) of interference of the in-cylinder pressure $P_{s}$ before starting with running of internal combustion engine during operation of the air compressor driven with electric motor: $\tau$ - time, $f$-frequency

Fig. 4 shows the time-domain and spectrum of in-cylinder pressure signal of the engine by measuring circuit powered from the marine power plants and portable computer powered by the power supply. The plot shows the interference in exchange process of working medium about frequency $50 \mathrm{~Hz}$. Fig. $4 \mathrm{~b}$ shows important components that are total multiple of the network frequency. Fig. 5 shows a fragment of a high-distortion time waveform that includes an outlet and an inlet process where the pressure is close to atmospheric. The Butterworth filter was used in the signal acquisition program, but the time-domain course obtained was almost identical to Fig. 4a.

When measuring circuit powered from the laboratory network through separation transformer and the laptop powered by the power supply, the time-domain and spectra were obtained shown in Fig. 6. From the plot one can see, that significant interferences remained. However at applying separation transformer and powering the computer 
without the power pack the disturbances were significantly reduced (Fig. 7).

a)

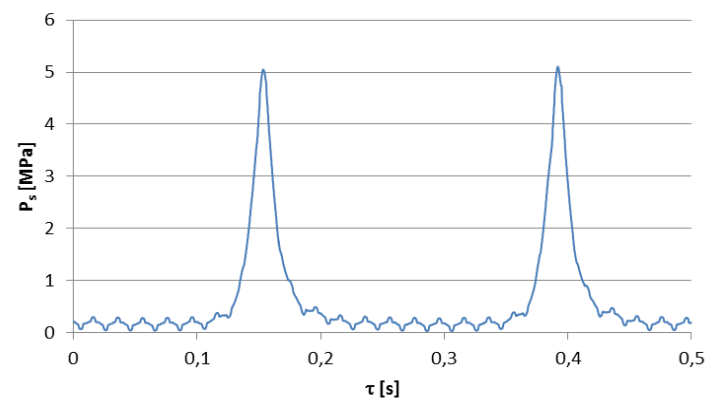

b)

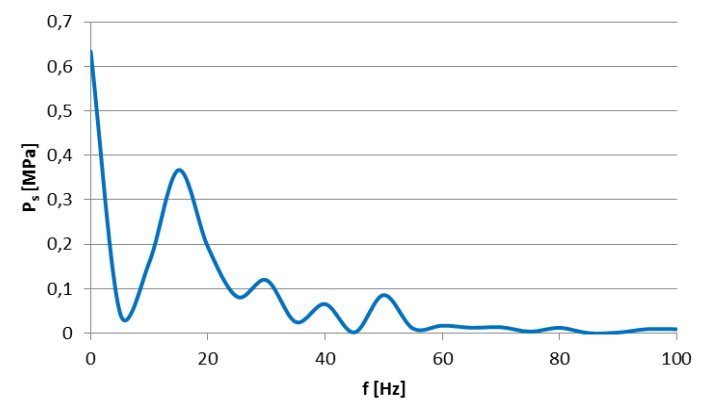

Fig. 3. Time-domain a) and the spectrum b) of incylinder pressure signal of the internal combustion engine at the measuring circuit fed from the UPS power supply

a)

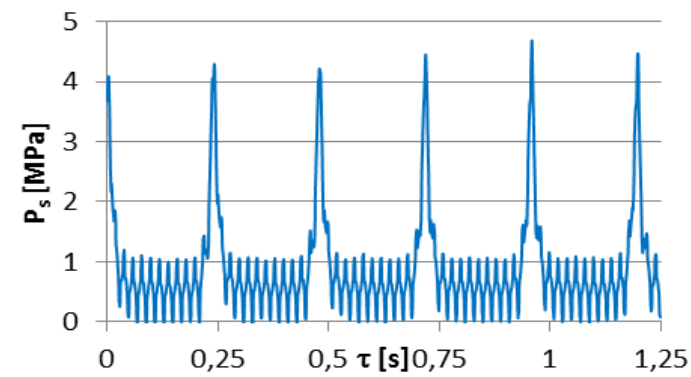

b)

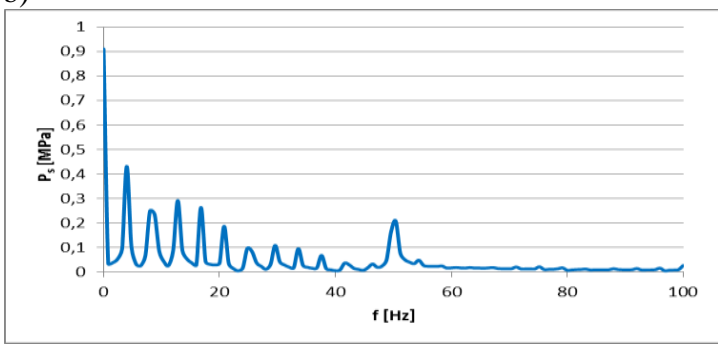

Fig. 4. Time-domain a) and spectrum b) of incylinder pressure signal of the internal combustion engine by the test by measuring circuit supply from the laboratory network and portable computer from the power supply in frequency band $0 \div 0.8 \mathrm{kHz}$

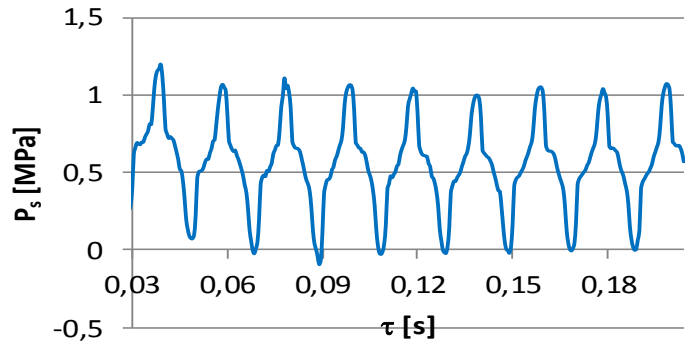

Fig. 5. Fragment of the time-domain of the interference signal

However, the most disturbances were reduced at the measuring circuit powered from the laboratory network and the portable computer powered by battery (Fig. 8).

a)

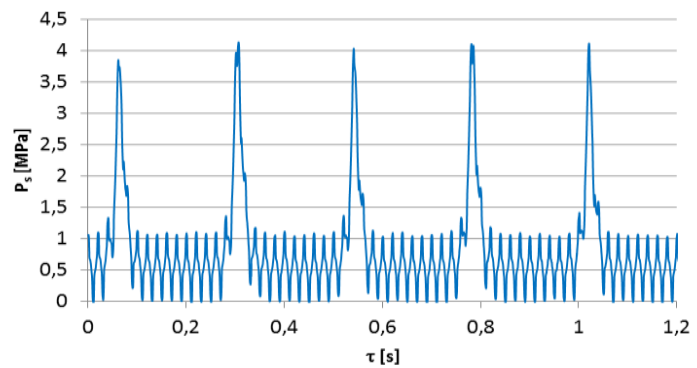

b)

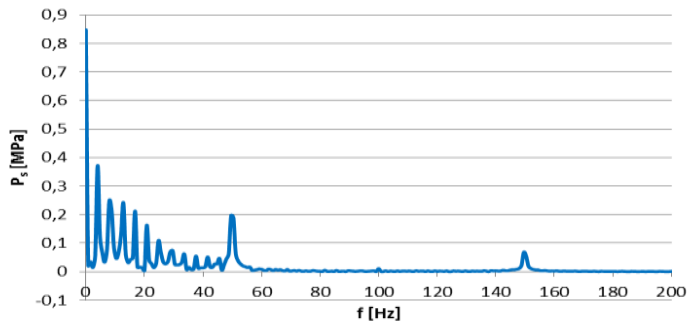

Fig. 6. Time-domain a) and spectrum b) of incylinder pressure signal of the internal combustion engine when the measuring circuit powered by the separation transformer and the computer from the power supply in the frequency range $0 \div 800 \mathrm{~Hz}$

To the global assessment of the various ways interference elimination statistical measures were appointed (amplitude estimates) and kurtosis [15], and the results are summarized in Fig. 9. From the drawing clearly shows that the most effective way of interference reduce turned out to be an effective of the measuring circuit powered to be directly from the laboratory network, and laptop from battery by disconnecting the power supply. The highest effective value and the average of the signal appeared in at powering the measuring circuit by the isolating transformer, and of computer from the power supply. 


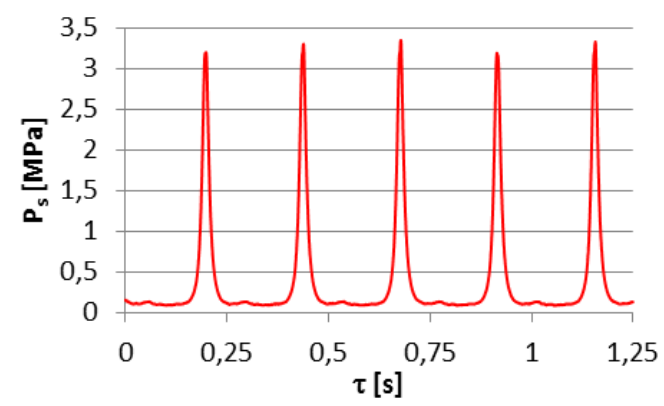

Fig. 7. Time-domain of cylinder pressure using the separation transformer and at powering the computer from battery without power supply

a)

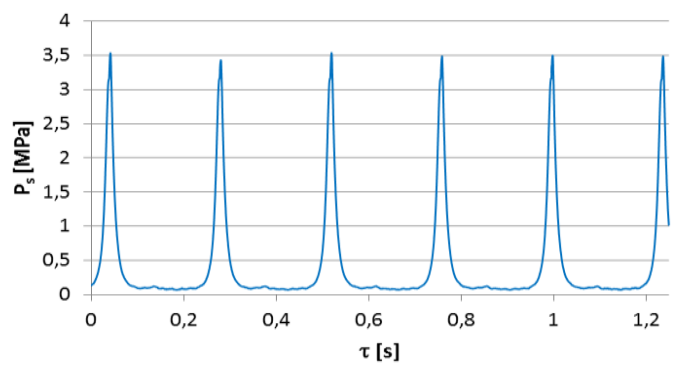

b)

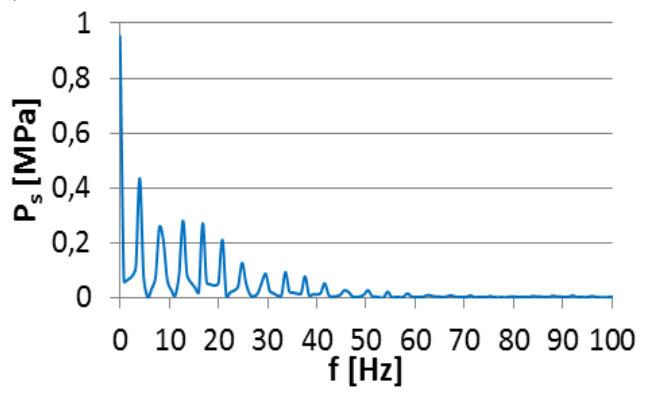

Fig. 8. Time-domain a) and spectrum b) of incylinder pressure signal of the internal combustion engine at the measuring circuit powering from the laboratory network and portable computer from battery in frequency band $0 \div 100 \mathrm{~Hz}$

\subsection{Wavelet analysis of signals}

The signal from Fig. 4 was subjected to the denoise process in Matlab programme and is shown in Fig. 10. It can be seen that de-noise was not very effective.

$P_{s}(\tau)$ signal can be presented as a theme sufficiently smooth the course and some fluctuations (details). A wavelet transform were used to decompose the signals to separate the usable signal from noise. During the decomposition the signal is decomposed into low-pass $(a)$ and high-pass $(d)$ elements:

$P_{s}=a_{1}+d_{1}=a_{2}+d_{2}+d_{1}=a_{3}+d_{3}+d_{2}+d_{1}(7)$

Signal synthesis process is carried out according to the same algorithm in the reverse direction. This record shows the decomposition of the original signal Fig. 11 shows a Haar wavelet decomposition to level 5 .

In this way was separated the useful signal of pressure course in the cylinders from interference.

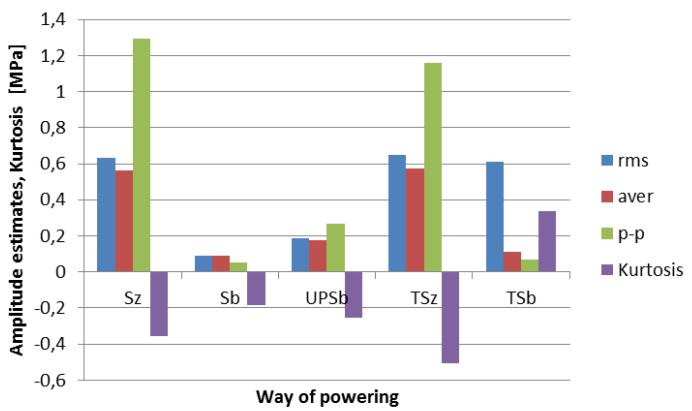

Fig. 9. Influence of the way of powered of measurement circuit and computer on the values of amplitude estimates and kurtosis of disturbaced of the courses of in-cylinder pressure signal of the internal combustion engine: $\mathrm{Sz}$ - powering from the network and the computer from the power adapter, $\mathrm{Sb}$ - power supply from the mains and the computer from the battery, UPSb - power of measurement circuit from netwok by the power pack UPS and of computer from the battery, TSz - powering from the network the measuring circuid from the network by the separation transformer and of computer from the power pack, TSb - powering from the measuring

circuid from the network by the separation transformer and of computer from the battery

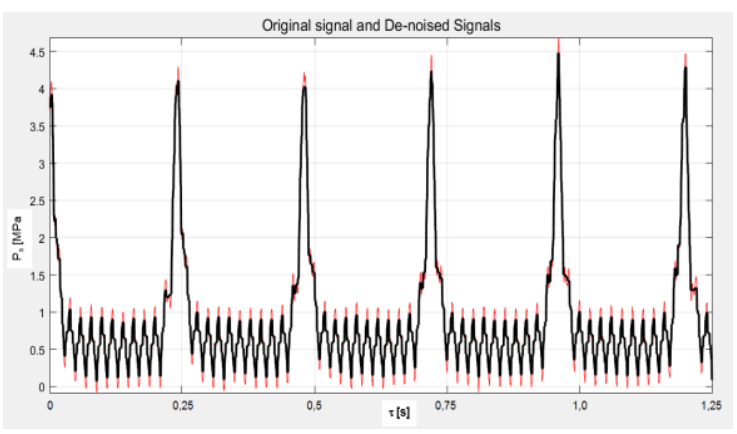

Fig. 10. The original and de-noised course of incylinder pressure signal when powering the measurement circuit from the network and the computer from the power supply

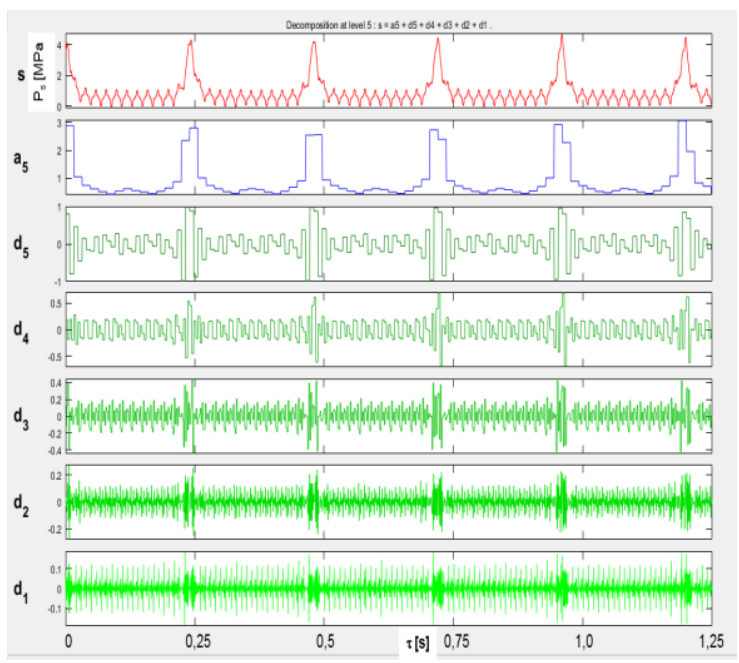

Fig. 11. Haar wavelet decomposition of the distorted course signal of in-cylinder pressure when the measurement circuit powered from the network and computer from the power supply 


\section{CONCLUSIONS}

At work an attempt was made to identification the sources of interference and it was examined experimentally ways of their transmission. It can be seen that the interferences penetrated to the measuring apparatus by the power network. In the case of diagnostic tests of internal combustion engines on seagoing vessels, their results are also disrupted.

During analysis of the measurement data sequence, can be exposed the noise components of small and large frequencies. A systematic disturbance occurs when diagnosing of marine engine room objects, that is can contribute to erroneous diagnostic decisions. In order to obtain credible results, it is necessary to minimize errors and interferences of measures at the stage of processing stage and signals analysis.

Based on the studies conducted, it can be concluded that the measuring interference reduction in-pressure signals in of the engine is possible. The most effective method proved to be that, when the computer is powered only from the battery, and the measuring circuit directly from power network of the marine power plant.

The use of the computer power supply causes the introduction of significant interference that may adversely affect engine diagnostic decisions using the in-cylinder pressure signal. Ineffective method, proved to be applicable to the measuring circuit of the separation transformer. Not only did it not help to reduce interference, but it also introduced additional errors due to increased signal interference.

The tests conducted for the same type of measurement and the same measuring circuit indicate the presence of network electrical interferences and from some objects, which shows improvement in the state when the computer with the acquisition and signals analysis system is autonomous powered.

It is planned to carry out further research on the subject, in order to develop effective noise reduction methods when diagnosing internal combustion engines, which is the condition for a credible decision.

\section{SOURCE OF FUNDING}

This research outcome has been achieved under the research project "Ecological and economic aspects of the operation of selected elements of marine power systems" No. 1/S/IESO/2014 financed from a subsidy of the Ministry of Science and Higher Education for statutory activities.

\section{REFERENCES}

1. Aminghafari M, Cheze N, Poggi JM. Multivariate denoising using wavelets and principal component analysis. Computational Statistics \& Data Analysis 2006; 50: 2381-2398.

2. Busch S, Zha K, Warey A, Pesce F, Peterson R. On the reduction of combustion noise by a closecoupled pilot injection in a small-bore DI diesel engine. ASME 2015 Internal Combustion Engine Division Fall Technical Conference. Houston, 8-11 November; 2015; 2: 1-18.

3. Hasse L, Kołodziejski J, Konczałowska A, Spiralski L. Interference in electronic equipment, Radioelectronic; Warsaw 1995. Polish.

4. Kim KS, Szedlmayer MT, Kruger KM. Kweon C M. Optimization of In-Cylinder Pressure Filter for Engine Research. US Army Research Laboratory, Technical Report; 8034; Jun 2017: 1-38.

5. Koustav D. Characterization and rejection of noise from in-cylinder pressure traces in a diesel engine. Electronic Theses and Dissertations 2012: Paper 121.

6. Mindykowski J. Why does the electrical power quality problem in ship's systems deserve special attention? Electrotechnical Review 2004; 6: 535-543. Polish.

7. Monieta J. Interference Reduction Selected Measurement Signals of Ships. Bulletin of the Military University of Technology 2014; 63(3): 91102. Polish.

8. Monieta J. The application in-cylinder pressure course in different domains for diagnostics of medium speed marine diesel engines in operation conditions. Combustion Engines 2013; 154(3): 153-160. Polish.

9. Monieta J. The identification and elimination of interference in pressure course in the cylinders of internal combustion engines measured under marine power plant exploitation conditions, Scientific Journal of Polish Naval Academy 2015 2: 47-55.

10. Payri F, Broatch A, Tormos B, Marant V, New methodology analysis-cylinder pressure direct injection Diesel - application for combustion noise, Measurement Science and Technology 2005; 16: 540-547.

11. Payri F, Lujan JM, Martin J, Abbad A. Digital signal processing of in-cylinder pressure for combustion diagnosis of internal combustion engines; Mechanical Systems and Signal Processing; 2010; 24: $1767-1784$ http://dx.doi.org/10.1016/j.ymssp.2009.12.011.

12. Polanowski S, Wysocki H. Wavelet decomposition a indicator diagram marine engine using wavelet explorer. Scientific Journal of Polish Naval Academy 2005; 160(1): 131-150. Polish.

13. Radan D, Sørensen AJ, Ådnanes AK, Johansen TA. Reducing power load fluctuations on ships using power redistribution control. Marine Technology 2008; 45(3): 162-174.

14. Zarzycki J. Introduction to digital signal processing. Transport and Communication Publishers, Warsaw 2006. Polish.

15. Żółtowski B, Cempel C, (ed.), The engineering of the diagnostics of machine engines. Polish Society for Technical Diagnostics, Institute of Technology of Exploitation PIB Radom 2004. Polish 


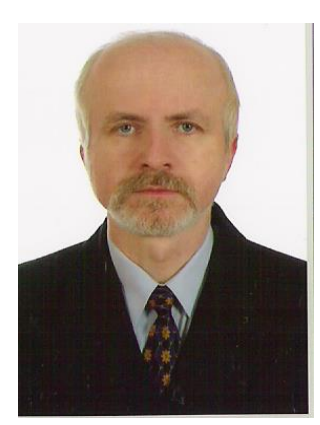

Jan MONIETA, DEng. Doctor in the Faculty of Mechanical Engineering at Maritime University of Szczecin. His main research areas cover operating, reliability, tribology and diagnostic of reciprocating internal combustion engines.

Eng. Marcin NOWICKI graduated the Faculty of Marine Engineering in Maritime University of Szczecin in 2015, about speciality the marine power plant operation. He works in Seatrans Chemical Tankers AS. 